Journal of World Englishes and Educational Practices (JWEEP)

ISSN: 2707-7586

Website: www.jweep.org

JWEEP

\title{
Pupils' Reading Comprehension, Problem-Solving Skills and Academic Performance
}

GLAIZA T. JALA

Teacher, Department of Education, Philippines

Corresponding Author: Glaiza T. Jala, E-mail: glaiza.jala@deped.gov.ph

\begin{tabular}{l} 
ARTICLE INFO \\
\hline Article History \\
Received: July 21, 2020 \\
Accepted: August 10, 2020 \\
Volume: 2 \\
Issue: 4 \\
\hline KEYWORDS
\end{tabular}

Reading Comprehension, Problem Solving Skills, Academic Performance

\begin{abstract}
The focal point of this research is to gauge the relationship between the reading comprehension level, problem-solving skills and academic performance of Grades 6 pupils of all the elementary schools in Carmen West District, Division of Bohol, Philippines. Specifically, this study sought to determine the academic performance of the elementary pupils in terms of four key subjects, namely: English, Science, Mathematics and other subjects such as Filipino, HEKASI, EPP and MAPEH. Further, this study presented also the profile of the pupils' reading comprehension based on the following levels: Literal, Interpretative, Critical-Analysis and Application and their problem-solving skills' profile. Pearson Moment Product Correlation Coefficient was employed to determine the correlation between the level of reading comprehension and the two identified variables, namely: academic performance and problem-solving skills of the respondents. To prove the validity and reliability of the obtained Pearson $r$, it was checked against the Table of Critical Values of the Pearson $r$ at .05 level of significance. On the reading comprehension level and academic performance, results unfolded that there is a significant correlation between reading comprehension and academic performance and this finding implies that the reading comprehension is a contributory factor to improve pupils' academic performance. Moreover, on the reading comprehension level and problem-solving skills, the result indicates that there is a significant correlation between reading comprehension and problem-solving skills. This study concludes that reading comprehension is a contributory factor to the improvement of pupils' academic performance and problem-solving performance. The researcher recommends that school administrators look into the possibilities of providing more supplementary materials in the form of books and other reading materials so that pupils can use it for further learning and to organize seminars and workshops, special trainings in order to fully equip the teachers with more knowledge and skills in teaching reading strategies. Teachers may organize functional educational programs, remedial classes and enrichment activities to improve pupils' comprehension skills through systematic comprehension instruction.
\end{abstract}

\section{Introduction}

English has been the universal language since billions of people in the world use it as medium of communication. It is considered as the gate way to the world of education, business, technology and inter-people communication. In fact, a famous writer said that the more people read English, the more they know. The significance of the proficiency of the language in all dimensions and facets of people's activities is indispensable. Thus, quality education in English has become imperative.

Among the wonderful technological discoveries which men of talent in the present have made with God's help, it is welcomed with special interest those that relate with communication. This is where language proficiency comes in. Proficiency in English

\footnotetext{
${ }^{1}$ Published by Al-Kindi Center for Research and Development. Copyright (c) the author(s). This is an open access article under CC BY license (https://creativecommons.org/licenses/by/4.0/)
} 
language is competence. Through competence, one can conquer the world that begets power to change the world. Further, it is believed to help an individual face and overcome problems and challenges in life. Thus, it has then become imperative for learning institutions to provide quality education especially in English. This is enforced by the Department of Education.

However, despite the truism and earnest efforts, the national achievement test in English last 2009 was below par. In fact, out of 985,754 pupils who took the NAT, 646,979 (65.6\%) were identified of having low mastery in English. It was stressed by Quijano(2009), that the recent result was alarming and must be given immediate action by all academic planners.

Further, data showed that pupils have poor academic performance. In 2009, the Department of Education (DepEd) conducted a National Achievement Test (NAT) to all public schools in the Philippines. The DepEd reports that there has been a 21.36 percent increase in NAT results from 2006 to 2009. The 2009 NAT revealed a rise in Mean Percentage Score (MPS) of only 66.33 percent from 54.66 percent in 2006 , which equates to an improvement of $11.67 \%$. The percentage gains were in all subject areas and pointed to a steady improvement in the primary education of the country's public-school system. It certainly speaks of a forward movement but a 66.33 MPS (from 54.66 in 2006) is still a rather low score, which, in fact, is only at the "near mastery level." The mastery level among grade 6 was only $14.4 \%$ and $1.1 \%$ with $4^{\text {th }}$ year high school students, which means that the mastery scores were staggering $85.6 \%$ among the former and $98.1 \%$ among the latter. This is more alarming.

One of the skills to be measured to ensure proficiency in communication is reading comprehension. Literally, it means understanding. It is essential in developing communicative competence. Lizardo (1999) as cited by Cagampang (2007)pointed out that reading is the most important subject in the school curriculum. He also emphasized that pupils could not learn the basic applications if they happen to be deficient in reading skills. So, one could see the importance of learning reading, per se, but more importantly, reading with comprehension.

Comprehension is to uncover avenues of communicating most readily, so people easily understand the world, hence the human society can rightly and harmoniously relate with each other. It is also considered critically important to the development of children's reading skills and therefore to the ability to obtain education. Indeed Durken (1993) noted that reading comprehension has come to be the "essence of reading", not only to academic learning in all subject areas, not only of single words and sentences but also of the interrelationship among sentences in a discourse.

Comprehension continues to be one of the most crucial areas of reading assessment and instruction. Although there is an abundance of research in this area, there still exist numerous problems that are to be given immediate and great concern. One of these concerns is how to improve the poor comprehension of the students in reading. Reading enables a person to unravel the mysteries of the world, explore accumulated knowledge and contemplate on the unknown. From his search, he begins to uncover the same answers to questions and is stimulated to raise more questions and to continue his pursuit of deeper understanding.

Indeed, reading is a vital part of problem-solving (Krulick and Rudnick, 1995). It is also a key to a deeper level of understanding. A high reading comprehension skill is indeed essential if one is to understand the mysteries of the world and contemplate the unknown. When people are able to read with understanding, then they indeed can acquire more knowledge of things.

Thus, the researcher was motivated to assess the level of reading comprehension of the Grade VI pupils of West Carmen District, Carmen, Bohol, Philippines to find out the correlation between pupils' reading comprehension skills with their problem-solving skills and academic performance. It is also hoped that the result of the study would be of great help in coming up with more tangible plan of activities to improve the reading comprehension skills in English as recommendations.

\section{Literature Review}

Reading is a basic tool in the educative process. In fact, countless learning institutions implement reading programs in order to help students develop their reading skills and cope with reading problems. It is also regarded as an integral part of the curriculum.

According to Rubin (1993), reading is a complex dynamic process that involves the bringing of meaning from the printed page. So, it is both a sensory and a mental process. It involves the use of the eye and mind. As cited by Arango (2007), 
comprehension is an active process where the reader interprets and constructs meaning from what he/she reads based on what he/she already knows about the topic.

Department of Education has singled out reading as an indispensable tool in the acquisition of functional literacy. Hence, schools are expected to provide various venues and opportunities for learners to engage in reading. Furthermore, educators have long acknowledged the importance of reading proficiency and so they have included in their repertoire of teaching strategies and various reading drills and activities which are aimed not only to help students excel in reading, but also to motivate them to have a deep sense of love and appreciation for it.

Quijano (2007) states, "Reading problem as the main culprit for the poor performance of some students in the NAT." In the current Philippine public school curricula for elementary and high school, reading (pagbasa), however, is just part of three other subjects - listening (pakikinig), speaking (pagsasalita) and writing (pagsusulat) - under English and Filipino. With the progressive reduction of class minutes, along with the fact that reading is combined with other subjects in one session, students will certainly have less time to devote to improving reading comprehension.

According to Villamin (1994), "Reading is a two-way process. It is a communication between the author and reader." With this communication of the reader and the author, a better learning will be established; but if there is communication gap, then it would result to poor comprehension. This is now the task of educators to help pupils read with comprehension so that there will be good teaching and learning process as the lesson goes on.

Reading comprehension means the act or the action of grasping with understanding as used in the study. It is measured in four levels; noting details, getting the main ideas, making inferences and making conclusion." (Digal, 2007). These levels are used by the teachers to develop students' reading comprehension and are important things to consider in having a better way of developing reading comprehension of the students.

According to Jason Carlos (2008), "Reading comprehension and overall academic achievement can be greatly involved, and learning gaps closed by systematically increasing the amount of academic background knowledge students learn beginning in the elementary grades." This means that reading comprehension and background knowledge are important to have a good academic achievement.

In Florida where students take rigorous Florida Comprehensive Assessment Test (FCAT) each year beginning grade 3, reading score data is consistent with nationwide trends. There is no doubt that reading instruction has improved in the state over the last decade and reading scores at elementary levels show commendable gains. The background knowledge extends beyond definitions.

Reading comprehension depends upon combining ideas in the passage with the prior knowledge.It involves metacognition according to Alcantara, et al 2005), which is the process of making hypothesis and testing them by making judgments about what one is reading. It is thinking about thinking. If a student's reading comprehension is poor, there's a tendency that his/her performance on other subjects will be affected

This study is anchored on the Schema Theory. This theory suggested that our knowledge and expectation about the world will strongly affect our ability to understand new information by providing a framework within which that new information might fit. Not surprisingly, a great deal of research with both first and second language readers has been carried out using schema theory. The basic principle behind schema theory is that texts themselves, whether spoken or written, do not carry meaning. Rather they provide signposts, or clues to be utilized by listeners or readers in reconstructing the original meaning of speakers or writers (Sir Frederick Bartlett,1932).

Reading comprehension is thus an interactive process between the reader and the text, in that the reader is required to fit the clues provided in the text to his or her background knowledge. Schema theory is related to bottom-up and top-down processing. According to schema theory, the process of interpretation is guided by the principle that every input is mapped against same existing schema and that all aspects of that schema must be compatible with the input information. This principle results in two basic models of information processing, called bottom-up and top-down processing. Bottom-up processing is evoked by the incoming data; the features of the data enter the system through the best fitting, bottom-up schemata. Schemata are hierarchically organized from most general at the top to most specific at the bottom. As these 
bottom-level schemata converge into higher level, more general schemata, these too become activated. Bottom-up processing is therefore called data-driven. Top-down processing, on the other hand, occurs as the system makes general predictions based on higher level, general schemata and then searches like input for information to fit into these partially satisfied, higher order schemata. Top-down processing is, therefore, called conceptually-driven.

Constructivism, which is generally attributed to Jean Piaget who articulated mechanism by which knowledge is internalized by learners, is a similar theory to schema. The theory emphasizes on the individual as creator rather than receiver of meaning. Thus, the opportunities for the teachers to find more effective strategies will be broadened. The author further expounded that during reading, world knowledge serves as both the foundation and the building blocks for constructing meaning. That is, the amount, type, and kind of prior knowledge a reader has about a given topic and the manner in which the reader links known and new knowledge affects the meaning he/she constructs for the immediate text. In addition to world knowledge, there's also text knowledge which contains all that the individual knows about how text is organized, how one processes text, how the language of text functions, what expectations are reasonable when approaching print, what procedures are useful in interacting with text, and countless other conventions of text and print.

The Input Hypothesis- Krashen's model affirmed the constructivist and the schema theory which explain how prior knowledge affect the reading process. The Input Hypothesis states that we learn a second language by understanding language containing linguistic structures that are just beyond the structures we already know. Krashen symbolizes it asi(input) + 1 .

This study is also anchored on the idea of Otto (1994), in Estoania, 2001) that views reading as a tool. It is a tool for learning all subject areas like English, Science, or Math. As stated by Rodil (1990, in Gaduya, 1994) "Reading is the key to learning in the total educative process."

In considering reading as a tool, it is important for an individual to be proficient in reading since it is in this stage that reading becomes an essential key to learning. Mindful of this information, the researcher believes that there is a strong relation between reading comprehension and academic success. In other words, a student who is a strong reader is more likely to do well in school and pass exams than a student who is a weak reader. So, to speak, a wider room for development is laid before individuals who read a lot. A child who knows and develops the fundamental skills in reading as early as his childhood has the great capability to achieve high academic success.

Krashen emphasizes that people acquire new structures in a second language (new words, new grammar rules, etc.) not by focusing on the structures themselves but by understanding the meaning of a communication containing those new structures (Ruddell, 2005). In reading, the person can live and travel vicariously and become acquainted with people and events in the past that have shaped his world. In this manner, every individual has to be competent and independent in order for him to cope with the changes that he has deal with. These changes which lead to knowledge explosion pave the way for efficient readers to excel in almost every field of specialization.

Initially, people learn to read, but therefore they read to learn. According to Alcantara, et al (2003), effective reading is reading with speed and comprehension. Speed in reading is relatively easy to achieve but developing comprehension, which is aconstellation of skills or abilities, is difficult. Whatever the motivation and the purpose, reading implies comprehension. It is worthy to note that reading is a continuous process which cannot be terminated when a person wants to learn.

It was also stressed further that reading is a deepening of perception and understanding through the inter communication of minds using the medium of written word. Reading is a part of meaning-making process (Goodman, 1996). It is a perceptive language process where readers are active users of language. The reader is seen as central to the act of reading (Goodman, 1996).

Still according to Goodman, reading is making sense of the text. As a reader reads, the text must be sampled and interpreted through the reader's unique personal background knowledge and experience. So, reading includes the development of attitudes, abilities and techniques. He further stated that the construction of meaning is the result of effective and efficient reading. He defined proficient reading as both effective and efficient. It's effective in that the reader is able to make sense; it's efficient in that this is accomplished with the least amount of time, effort and energy. An efficient reader uses only enough information from the published text to be effective. 
Comprehension refers to understanding and the ability to get the meaning of something (Rubin, 1993). Without understanding, there is no reading. Reading comprehension is a complex intellectual process involving a number of abilities. The two major abilities involve word meanings and verbal reasoning. Without word meanings and verbal reasoning, there would be no reading comprehension; without reading comprehension, there would be no reading.

Comprehension involves thinking. As there are various levels in the hierarchy of thinking, so are there various levels of comprehension. Higher level comprehension would obviously include higher level of thinking (Rubin, 1993). Comprehension is classified according to the level of thinking involved. It is otherwise known as the levels of comprehension, namely literal, interpretative, critical-analysis and application.

Literal comprehension represents the ability to obtain a low-level type of understanding by using only explicitly stated information. This requires lower thinking skills. Answering to literal questions simply demand what the student recalls from memory on what the text says (Adams \& Patterson, 2005).

Interpretative or interpretation level demands a higher level of thinking because the questions are concerned with answers that are suggested or implied by the text, but not directly stated. To answer questions at this level, readers must be able to work at various levels of abstraction. The interpretative level is one in which the most confusion exists when it comes to categorizing skills. The confusion concerns the term inference. Inference is something derived by reasoning, something that is not directly stated but suggested in the statement; a logical conclusion that is drawn from the statement (Rubin and Opitz, 2007).

Critical comprehension is the level of understanding that entails the distinguishing of fact from opinion; the recognition of an author's intent, attitude, or bias; the drawing of inferences; and the making of critical judgments. It is a more sophisticated level of understanding. A famous reading expert, Dr. Francis Triggs says, "Critical reading requires a contribution by both the author and reader and an interplay which usually results in a new understanding (Adams and Patterson, 2005).

Application level of comprehension uses divergent thinking skills to go beyond the literal comprehension, interpretation and critical reading levels. It involves the ability to link the material read with the personal experiences of the reader. In this level, the reader tries to come up with new or alternate solutions to those presented by the writer (Rubin and Opitz, 2007).

On the other hand, Knowledge of word meaning is essential on comprehension (Rubin, 1993). Quinn (1997) added that a good vocabulary is a vital part of effective communication. Educators prove that vocabulary instruction can improve the comprehension of the students.

Effective comprehension thus requires the ability to relate texts to reader's prior knowledge, since reader's personal and cultural background knowledge affects their interpretation and comprehension (Johnson, 1982 in Quinn 1997).

Thorndike stated that reading is a very elaborate procedure, involving a weighing of each of many elements in a sentence, their organization in the proper relations one to another to determine final response. He stated further that even the act of answering simple questions includes all the features and characteristics of typical reasoning.

Reading has been defined as the ability to recognize printed symbols and to comprehend their meaning. Furthermore, reading has been shown to be an essential skill for facilitating a multitude of day-to-day tasks and promoting an easily accessible means for recreation in today's highly complex, print oriented society. The teacher has an immense responsibility for instructing learners to read, not merely recognition of printed text but also for reading comprehension.

Hence, reading comprehension is the process of simultaneously constructing and extracting meaning through interaction and engagement with printed text. The success of a comprehension depends on a good match of reader skills, text difficulty, and task definition. Reader skills of vocabulary and background knowledge are particularly important. Task are defined differently by the demands of different text, different cultures, and by different disciplines. Approaches to comprehension instruction cannot ignore basic word-reading skills for struggling readers, but can usually promote active engagement with varied texts in both oral and literate modes, in pursuit of authentic learning goals. 
In Section 21, Article 1 of the Education Act of 1982 which states that: "The education system aims to provide a broad general education that will assist each individual, in peculiar ecology of his own society, to attain potentials as a human being participating in the basic functions of his own society, and acquire the essential education foundation of his development in to a productive and versatile citizen." Such legal provision underlines the importance of education as a foundation in the development of a human being into a productive and versatile citizen in the society.

Furthermore, it is also stated in Article XIV, Section 1 of the 1987 Philippine Constitution that "the State shall protect and promote the right of all to quality education at all levels and shall take appropriate steps to make education accessible to all." But despite the government's efforts as well as the school administrators' and teachers' pursuit towards quality education, many students experience difficulties in reading comprehension. Such is the challenge faced by our educators.

It is important that students possess the appropriate kinds of beliefs that reading comprehension is closely related to academic success, because applying comprehension requires effort and persistence. Students who believe through their experiences that the effort will pay off well comprehension. On the other hand, students who do not hold similar beliefs will not be motivated or persist long enough to achieve success. (Prawat, 1989 in Conley, 1995).

Holmes (1976, in Astronomo, 2006) maintains that reading is also the basis of comprehension to be able to recognize plenty of words with corresponding meaning. A person does not simply read to add to his store of information but also needs to get the meaning of ideas and facts that he is reading.

Thus, through this humble study, the researcher was motivated to determine the overall picture of the reading comprehension levels of the grade 6 pupils and its relationships towards their academic performance and problem-solving skills.

\section{Methodology}

\subsection{Design}

The study adopted the descriptive-correlation and documentary correlation method. It assessed the level of reading comprehension of the respondents and established the relationship between level of reading comprehension and academic performance and problem-solving skills.

\subsection{Environment}

The researcher conducted the study in 15 elementary schools in Carmen West District, Division of Bohol. These schools are situated in 14 different barangays in the Municipality of Carmen, Province of Bohol namely: Alegria Elem. School, Buenavista Elem. School, Calatrava Elem. School, Carmen West Central Elem. School, El Progreso, Katipunan Elem. School, Lapu-Lapu Elem. School, La Victoria Elem. School, Matin-ao Elem. School, Montesuerte Elem. School, Nueva Fuerza Elem. School, Tagaonan Elem, Villa Fuerte Elem. School, Villaflor Elem. School and Villarcayo Elem. School. They are headed by one Schools District Supervisor. These schools are public elementary schools.

\subsection{Participants}

The participants of this study are grade 6 pupils in 15 public Elementary Schools in Carmen West District, Division of Bohol. This study utilized the total population of the environment to see the real picture of the performance of all the grade 6 pupils of Carmen West District.

\subsection{Instrument}

Data gathering was based on standardized questionnaires from the national achievement test for Grade 6, from the book How to Increase Your Reading Speed L-10 Green park Extension, New Delhi by Ahuja G.C. and Pramila Ahuja and from the California Standards Test questions for Grade 6 Mathematics of California Department of Education, 2008.

A total of forty (40) items with 10 items for each level namely, literal, interpretative, critical-analysis and application level, with 15 items in Mathematics were provided in the test.

The grades of the grade 6 pupils of Carmen West District are the source to measure the academic performance. These were gathered through the grade 6 section advisers of all elementary schools in the district. 


\subsection{Statistical Treatment}

In the analysis of the data, the following procedures were followed. The responses were collected, tallied and tabulated.

To determine the profile of the respondents according to the academic performance of the pupils in terms of English, Science, Mathematical and other subjects, the grades and descriptions below were used.

$\begin{array}{ll}\text { Range } & \text { Description } \\ 95-100 & \text { Outstanding } \\ 89-94 & \text { Very Good } \\ 83-88 & \text { Good } \\ 77-82 & \text { Fair } \\ 70-76 & \text { Poor }\end{array}$

To get the overall picture of the level of reading comprehension among the respondents, the computation of the weighted mean was applied.

To determine the correlation between the level of reading comprehension and the two identified variables, namely: academic performance and problem-solving skills of the respondents, Pearson Moment Product Correlation Coefficient was used.

To prove the validity and reliability of the obtained Pearson $r$, it was checked against the Table of Critical Values of the Pearson $r$ at .05 level of significance.

\section{Results and Discussion}

\section{Academic Performance of the Pupils}

In English, there are 222 out of 521 pupils who have grades within the range of 77-82 which has the qualitative index of fair. 96 pupils have shown poor academic grades since they belong to the range of 70-76. These results imply that more than 50 percent of the pupils have not shown commendable English performance. Furthermore, it calls the attention of English teachers and coordinators to come-up with a set of activities to improve the academic performance of the pupils in the field of English.

In Science, 259 pupils belong to the range of $77-82$ and 94 pupils belong to the range of 70-76. It connotes that the pupils have shown poor academic performance in the field of science. This finding implies that the pupils have not achieved the desired commendable mark in science. Science demands analyses and computations where students have shown negative orientation based from researcher's observation.

In Mathematics, 216 pupils have fair academic grades which indicate that they belong within the range of 77-82. While 91 pupils have also shown poor grades in math. The result supports the claim that most of the pupils have negative notions about the subject which are supported by the poor grades in the subject. Further, it is also observed by the teachers that the pupils have lukewarm attitude and self-concepts towards mathematics.

On the remaining subjects, namely: Filipino, EPP, HEKASI, and MSEP, the pupils have not shown commendable grades. 247 pupils have grades within the range of 77-82 which have the qualitative index of fair while 37 pupils have poor grades within the range of 70-76. The results indicate that the pupils have not performed satisfactorily in the five remaining subjects.

Generally, the pupils have shown academic grades which are not commendable. This finding supports the observations of the teachers that the pupils nowadays have poor academic performance due to lack of focus and negative attitudes towards studies.

\section{Pupils' Performance on Reading Comprehension Skills}

The first level in the reading comprehension is the literal. It shows that the computed mean of 6.37 which is the largest mean of all the skills and it is greater than the median of 6 . The result indicates that the curve of distribution of score is skewed to the right since the mean is on the right side of the median. The curve that is skewed to the right shows that many of the pupils 
got low scores and the given skill is difficult for them. To sum it all, the pupils are found to have a low performance in this reading comprehension skill. The computed standard deviation is the measurement of spread having a value of 1.73.

The second level is the interpretative. This level of performance has a total possible score of 10 . The computed mean score is 4.40 with standard deviation of 1.490 . The median which is equal to 4 is lesser than the mean. Therefore, the curve of distribution is skewed to the right which means that many of the pupils got low scores than those with higher scores. Furthermore, it illustrates that the pupils have not achieved the desired competence in the interpretative comprehension.

The third level is critical-analysis. It is the level of understanding that entails the distinguishing of fact from opinion; the recognition of an author's intent, attitude, or bias; the drawing of inferences; and the making of critical judgments. It is a more sophisticated level of understanding. The mean score is 4.90 with a standard deviation of 1.68 . It can be observed that the median of 4 is lesser than the mean. Therefore, the curve of their distribution is skewed to the right, which means that the majority of the pupils got low scores than those with high scores. The results show that the pupils failed to exhibit competence in critical analysis.

The fourth level is application which refers to the ability to link the material read with the personal experiences of the reader. In this level, the reader tries to come up with new or alternate solutions to those presented by the writer. It reflects that the computed mean of 4.59 which is lesser than the median of 4 which indicates that the distribution of the scores is skewed to the right. The result implies that the pupils have not exhibited competence on connecting the readings with their personal experiences.

Generally, reading comprehension got a total mean of 20.26 with a standard deviation of 4.14. Moreover, the median is 18 . The results show that the median is lesser than the mean which indicates the curve of distribution is skewed to the right. It illustrates that many got low scores than those with high scores. Furthermore, the finding connotes that the pupils failed to exhibit competence towards reading comprehension skills.

\section{Pupils' Performance on Problem Solving Skill}

It shows that the mean is 5.247 with a standard deviation of 3.34. The median which is equal to 4 is lesser than the mean. Therefore, the curve of distribution is skewed to the right which means that many got low scores than those with high scores. Moreover, the pupils did show difficulty in problem solving which indicates that the pupils need to be given more drills as to improve their competence in the skills in problem solving.

\section{Relationship between Reading Comprehension and Problem-Solving Skills}

It shows that the computed $r$-value which is equal to 0.384 which has the equivalent computed t-value of 9.474 is lesser than the critical value of 1.960. The results indicate the rejection of the null hypothesis of no significant correlation. The results support the findings of Thorndike, who stipulated that mathematical problem-solving correlates with reading comprehension and David and Phyllis Whitin who also claimed that "reading is a way that learners can make their mathematical thinking visible". Thus, reading comprehension is a predictor of one's performance in problem solving or vice versa.

\section{Relationship between Pupils' Reading Comprehension Skills and their Academic Performance}

In the overall academic performance, it reflects that the computed r-value of 0.664 which has the computed t-value of 20.230 is lesser than the critical value of 1.960. The result indicates that there is a significant correlation between reading comprehension and academic performance. Moreover, the finding implies that the reading comprehension is a contributory factor to improve pupils' academic performance. In other words, the competence of pupils towards reading comprehension is a factor affecting their academic grades.

In English, the computed r-value of 0.602 which has the computed t-value of 17.70 is lesser than the critical value of 1.960. The result indicates that there is a significant correlation between reading comprehension and English performance. Moreover, the finding implies that the reading comprehension plays a vital role in improving pupils' English performance.

In Math, the computed r-value of 0.561 which has the computed t-value of 15.44 is lesser than the critical value of 1.960 . The result indicates that there is a significant correlation between reading comprehension and Mathematics performance. Meaning, the competence of pupils towards reading comprehension is a factor affecting their Mathematics grades. 
In Science, the computed r-value of 0.629 which has the computed t-value of 18.43 is lesser than the critical value of 1.960 . The result indicates that there is a significant correlation between reading comprehension and pupils' performance in Science. This means that pupils with high level of reading comprehension have high grades in Science.

In other subjects, particularly MSEP, Filipino, HEKASI and EPP, the computed r-value of 0.65 which has the computed t-value of 19.49 is lesser than the critical value of 1.960 . The result indicates that there is a significant correlation between reading comprehension and pupils' performance in other subjects. This means that reading comprehension plays a significant role in improving the pupils' performance in other academic subjects.

\section{Conclusion}

This study is aimed to determine the relationship between the reading comprehension level, problem-solving skills and academic performance. Based on the foregoing results, the study reveals that reading comprehension is a contributory factor to the improvement of pupils' academic performance and problem-solving performance. Hence, the competence of pupils in reading comprehension relates to their academic performance and problem-solving performance. In the light of the findings and the conclusions, it is recommended that School administrators have to look into the possibilities of providing more supplementary materials in the form of books and other reading materials so that they can use it for further learning towards reading comprehension and teachers should provide enrichment classes that would cover reading comprehension and problem solving since these are very useful for the improvement and familiarization of different approaches in solving problems. Moreover, the pupils should be exposed more on mathematical verbal problems to enhance their skills both in reading comprehension and problem-solving. A follow up study is recommended to consider some factors affecting academic performance of the pupils.

\section{References}

[1] Ahuja G.C. and Pramila, A. (1999). How to increase your reading speed. L-10, Green Park Extension, New Delhi.

[2] Ajoc, Rowin B. et al. (2002). Problem-Solving Skills, Conceptual and Procedural Understanding on Fraction of First Year High School

Students. [Unpublished Thesis]

[3] Alcantara, et.al. (2003). Teaching strategies 1 for the teaching of the communication arts: listening, speaking, reading and writing. Katha Publishing Co., Inc. Makati City.

[4] Astronomo, M. et al.(2006). Student Teacher's Vocabulary Competence in Relationto Reading Comprehension. [Unpublished Thesis]

[5] Aupe, Lee C, et al. (2002). Gender Differences on Mathematical Problem Solving Among High Ability Fourth Year High School Students.

[Unpublished Thesis]

[6] Blickenstaff, J. (2012). The Effects of Reading Strategies in Comprehension of Elementary Age Learners. Retrieved November 29, 2012

from http://sophia.stkate.edu/cgi/viewcontent.cgi?article=1001\&context=maed

[7] Conley, M. (1995). Content reading instruction, communication approach. Michigan State University.

[8] Duke, N. (2002). Effective Practices for Developing Reading Comprehension. Retrieved September 3 , 2016 from https://lincs.ed.gov/professional-development/resource-collections/profile-348

[9] Estoquia, M.J. et al. (2001).The Reading Comprehension Level of Education Students of Divine Word College of Tagbilaran. [Unpublished Thesis]

[10] Gaduyon, M.L. (1994). Developmental reading English for academic purposes. Iloilo City.

[11] Israel, S. (2009). Handbook of Research on Reading Comprehension. Retrieved October 10, 2012 from http://www.eduhistory.com/reading-comprehension

[12] Krulik, S. and Rudnick, J. (1995). Teaching Reasoning and Problem Solving in Elementary School. Needham Heights Massachusetts.

[13] Martinez, J. and Martinez, N. (1996). Math without fear. Needham Heights Massachusetts.

[14] Quinn, S. and Irvings, S. (1997). Active Reading in the Arts and Sciences, Third Edition. Needham Heights, Massachusetts Boston.

[15] Rubin, D. (1993). A practical approach to teaching reading 2nd Edition. Trenton State College, USA.

[16] Ruddell, M.R. (2005) Teaching Content Reading and Writing. John Wiley and Sons, Inc. USA.

[17] Taplin, M. (2000). Mathematics Through Problem Solving. Retrieved October 16, 2012 from http://www.mathgoodies.com/articles/problem-solving.html

[18] Whimbey, A. (1999). Problem Solving and Comprehension $6^{\text {th }}$ Edition. Retrieved November 3 , 2012 from https://www.questia.com/read/10088252/problem-solving-and-comprehension 